\title{
Effect on histamine responsiveness of reducing airway dimensions by altering posture
}

\author{
Y T Wang, C I Coe, N B Pride
}

\begin{abstract}
Baseline airway geometry is thought to be an important determinant of the airway response to challenge; this geometry is altered by changing posture. The effect of changes in posture on airway calibre, midtidal lung volume, and the airway response to inhaled histamine was studied in eight healthy subjects (four female; mean (SD) age 29.8 (5.1) years, FEV $13.54(0.65)$ 1). Each subject was studied in both sitting and supine postures on two days; airway calibre was assessed by measuring total respiratory resistance (Rrs) at $6 \mathrm{~Hz}$ with a forced oscillation technique applied over 16 seconds of tidal breathing. Appropriate doses of histamine were selected by preliminary experiments and were always inhaled with the subject in the supine posture. Midtidal lung volume was larger in the sitting $(2.9(0.8) 1)$ than in the supine posture $(2.4(0.5) 1)$. Baseline Rrs was lower in the sitting than in the supine posture $(2.03(0.44)$ and $3.12(0.76) \mathrm{cm} \mathrm{H}_{2} \mathrm{O} .1^{-1}$. $\left.\mathrm{s}^{\star}\right)$. The mean absolute increase in Rrs after the same dose of histamine was $1 \cdot 22 \mathrm{~cm} \mathrm{H}_{2} \mathrm{O} .1^{-1}$. s in the sitting position $(65 \cdot 8 \%$ increase over baseline) and $1.39 \mathrm{~cm} \mathrm{H}_{2} \mathrm{O} .1^{-1}$. s (48.8\% increase over baseline) in the supine position. The geometric mean provocation concentration of histamine causing a given percentage increase in Rrs was similar in the sitting $(8.26 \mathrm{mg} /$ $\mathrm{ml})$ and supine $(8.65 \mathrm{mg} / \mathrm{ml})$ positions. Thus there was no significant increase in responsiveness after the reduction of airway dimensions and extra-airway distending forces that occurs in the supine posture.
\end{abstract}

Initial airway geometry is thought to be an important determinant of the response of the airways to challenge procedures. As originally pointed out by Bouhuys, ${ }^{1}$ when airway wall volume is constant the reduction in external airway circumference that occurs with reduction in lung volume must be associated with an increased wall thickness and a disproportionate reduction in internal airway calibre. The increased wall thickness may itself increase apparent airway responsiveness. ${ }^{1-3}$ In normal subjects airways resistance during tidal breathing increases in the supine posture

$\star_{1} \mathrm{~cm} \mathrm{H}_{2} \mathrm{O}=0.0981 \mathrm{kPa}$. owing to the reduction in end expired volume (functional residual capacity, FRC). Experiments using two different types of body plethysmograph showed that the increase in resistance was due to a passive decrease in airway dimensions as a result of the reduction in lung volume and recoil pressure. ${ }^{4}$ In 1963 Bouhuys $^{1}$ showed that, after inhalation of a standard dose of histamine, nitrogen clearance from the lungs was slower in the supine than the sitting posture. To our knowledge no direct comparison of bronchial responsiveness in the two postures has been made, probably because measurements of resistance are difficult in the supine posture. We have adapted the oscillation method to measure respiratory resistance in different postures and have compared bronchial responsiveness to inhaled histamine in the sitting and supine postures in eight symptomless subjects. Apart from examining the effects of posture-which may be relevant to nocturnal asthma-the experiment provides a convenient physiological method for comparing responsiveness at different baseline airway diameters without inducing changes in bronchial muscle tone with drugs.

\section{Methods}

SUBJECTS (table 1)

We studied eight subjects (four of them male; mean age 29.8 years) known to have measurable responsiveness to histamine, all of whom worked in our medical school and had never smoked. Two gave a history of mild asthma (subjects 2 and 8 ) but they had had no symptoms and had taken no bronchodilators for the two weeks preceding the study; the remaining six subjects had no respiratory symptoms or past history of significant respiratory disease though three were atopic with positive prick skin tests to common inhaled antigens. One of the mildly asthmatic subjects (subject 2 ) had a slightly reduced forced expiratory volume in one second $\left(\mathrm{FEV}_{1}\right)$ but baseline values were virtually constant when measured shortly before each of the four tests of histamine response. The study was approved by the Research Ethics Committee of this Medical School.

\section{MEASUREMENTS}

Spirometry and lung volume measurements Slow expiratory vital capacity (VC) and forced expiratory volume in one second $\left(\mathrm{FEV}_{1}\right)$ were measured using a dry spirometer (Vitalograph) and peak expiratory flow (PEF) with a 
Table 1 Baseline lung function (sitting) and bronchial responsiveness (supine) in the eight subjects

\begin{tabular}{|c|c|c|c|c|c|c|c|c|c|c|c|c|c|}
\hline \multirow{2}{*}{$\begin{array}{l}\text { Subject } \\
\text { No }\end{array}$} & \multirow[b]{2}{*}{ Sex } & \multirow{2}{*}{$\begin{array}{l}\text { Age } \\
(y)\end{array}$} & \multirow{2}{*}{$\begin{array}{l}\text { Height } \\
(m)\end{array}$} & \multirow{2}{*}{$\begin{array}{l}\text { Weight } \\
\text { (kg) }\end{array}$} & \multicolumn{2}{|c|}{$F E V_{1}$} & \multicolumn{2}{|l|}{$V C$} & \multicolumn{2}{|l|}{$P E F$} & \multirow{2}{*}{$\begin{array}{l}s G a w \\
\left(\mathrm{~cm} \mathrm{H}_{2} \mathrm{O}^{-1} \cdot s^{-1}\right)\end{array}$} & \multirow{2}{*}{$\begin{array}{l}T L C \\
\text { (l) }\end{array}$} & \multirow{2}{*}{$\begin{array}{l}P C_{20} \dagger \\
(m g / m l)\end{array}$} \\
\hline & & & & & (l) & (\% pred) & (l) & (\% pred) & $(l / \min )$ & (\% pred) & & & \\
\hline $\begin{array}{l}1 \\
2 \\
3 \\
4 \\
5 \\
6 \\
7 \\
8\end{array}$ & $\begin{array}{l}\mathbf{F} \\
M \\
M \\
M \\
M \\
F \\
F \\
F\end{array}$ & $\begin{array}{l}24 \\
32 \\
26 \\
32 \\
26 \\
27 \\
31 \\
40\end{array}$ & $\begin{array}{l}1.52 \\
1.85 \\
1.75 \\
1.72 \\
1.73 \\
1.64 \\
1.69 \\
1.74\end{array}$ & $\begin{array}{l}57 \\
75 \\
58 \\
70 \\
72 \\
57 \\
64 \\
65\end{array}$ & $\begin{array}{l}2.55 \\
3.35 \\
3.95 \\
4.75 \\
3.73 \\
3.16 \\
3.63 \\
3.16\end{array}$ & $\begin{array}{r}(90) \\
(83) \\
(101) \\
(128) \\
(103) \\
(114) \\
(127) \\
(112)\end{array}$ & $\begin{array}{l}2 \cdot 87 \\
4 \cdot 75 \\
4 \cdot 90 \\
5 \cdot 40 \\
4 \cdot 59 \\
3 \cdot 59 \\
4 \cdot 53 \\
4 \cdot 16\end{array}$ & $\begin{array}{r}(95) \\
(91) \\
(101) \\
(114) \\
(107) \\
(113) \\
(138) \\
(128)\end{array}$ & $\begin{array}{l}390 \\
410 \\
500 \\
625 \\
525 \\
476 \\
426 \\
426\end{array}$ & $\begin{array}{r}(98) \\
(66) \\
(83) \\
(106) \\
(91) \\
(111) \\
(98) \\
(98)\end{array}$ & $\begin{array}{l}0 \cdot 18 \\
0 \cdot 13 \\
0 \cdot 23 \\
0 \cdot 24 \\
0 \cdot 13 \\
0.22 \\
0 \cdot 17 \\
0.09\end{array}$ & $\begin{array}{l}3 \cdot 8 \\
5 \cdot 5 \\
6 \cdot 2 \\
6 \cdot 8 \\
4 \cdot 9 \\
4 \cdot 1 \\
5 \cdot 2 \\
5 \cdot 3\end{array}$ & $\begin{array}{r}5.9 \\
19.5 \\
16 \cdot 1 \\
13.6 \\
6.4 \\
12.7 \\
17.3 \\
1.5\end{array}$ \\
\hline $\begin{array}{l}\text { Mean } \\
\text { SD }\end{array}$ & & $\begin{array}{r}29 \cdot 8 \\
5 \cdot 1\end{array}$ & $\begin{array}{l}1 \cdot 71 \\
0 \cdot 10\end{array}$ & $\begin{array}{r}64 \cdot 8 \\
7 \cdot 1\end{array}$ & $\begin{array}{l}3.54 \\
0.65\end{array}$ & $\begin{array}{l}(107) \\
(16 \cdot 2)\end{array}$ & $\begin{array}{l}4 \cdot 35 \\
0 \cdot 80\end{array}$ & $\begin{array}{c}(111) \\
(16 \cdot 0)\end{array}$ & $\begin{array}{l}472 \\
77 \cdot 3\end{array}$ & $\begin{array}{l}(94) \\
(14 \cdot 1)\end{array}$ & $\begin{array}{l}0.17 \\
0.053\end{array}$ & $\begin{array}{l}5 \cdot 2 \\
0.99\end{array}$ & $9 \cdot 24$ \\
\hline
\end{tabular}

* Mean of the four measurements made before responsiveness was measured on days $C$ and $D$.

+ The measurement was made on day $\mathrm{A}$ in the supine posture and was used to choose histamine doses 1 and 2 for days $\mathrm{C}$ and $\mathrm{D}$; the geometric mean is shown.

Conversion: $1 \mathrm{~cm} \mathrm{H}_{2} \mathrm{O}^{-1} \cdot \mathrm{s}^{-1}=10 \cdot 2 \mathrm{kPa}^{-1} \cdot \mathrm{s}^{-1}$.

$\mathrm{FEV}_{1}$ - forced expiratory volume in one second; VC—slow vital capacity; PEF-peak expiratory flow; sGaw-specific airway conductance; TLC—total lung capacity; $\mathrm{PC}_{20}$-provocative concentration of histamine causing a $20 \%$ rise in $\mathrm{Rrs}_{6}$.

Wright peak flow meter. The largest value from three satisfactory attempts is reported. Total lung capacity (TLC) and specific airways conductance (sGaw) were measured by body plethysmography. ${ }^{56}$ Values were compared with standard reference values. ${ }^{7}$

\section{Total respiratory resistance}

The forced oscillation technique and equipment described by Landser et $a l^{8}$ was used to obtain total respiratory resistance (Rrs), the frequency dependence of resistance, and the resonant frequency. The subject, wearing a nose clip, breathed tidally on a mouthpiece attached to the oscillation apparatus. To minimise dissipation of the applied flow in the upper airway, the cheeks and floor of the mouth were supported by the palms of the hand, and the head and neck were slightly extended. The oscillation apparatus consisted of a loudspeaker attached to a tube leading to a screen pneumotachograph adjacent to the mouthpiece. A bias flow introduced through a side arm and extracted via a second side arm prevented changes in inspired oxygen and carbon dioxide. A complex signal of sinusoidal sound wave oscillations containing all harmonics of $2 \mathrm{~Hz}$ up to $26 \mathrm{~Hz}$ was applied by the loudspeaker. This signal was presented as preprogrammed pseudo random noise, the 0.5 second sequence being repeated every 0.5 seconds for 16 seconds. The peak to peak amplitude of the applied pressure was less than $2 \mathrm{~cm} \mathrm{H}_{2} \mathrm{O}$. During oscillation the impedance (ratio of the amplitudes of applied pressure and flow) of the subject's respiratory system was obtained from measurements of mouth pressure (from a lateral port close to the mouthpiece) and flow from the pneumotachograph. Pressure and flow were measured with identical differential pressure transducers (Validyne MP45). The apparatus was checked to ensure that the response of both transducers and attached tubing was matched at all frequencies up to $26 \mathrm{~Hz}$, a reference linear resistance being used. Pressure and flow signals were fed into a Fourier analyser, ensemble averaged over the measurement period of 16 seconds, and calculated to give values of impedance at $2 \mathrm{~Hz}$ intervals up to $26 \mathrm{~Hz}$. The impedance signal was further analysed as the in phase component of pressure and flow (resistance) and the out of phase component (reactance). The reliability of the derived values was indicated by a coherence function for each frequency. This function is the equivalent in the frequency domain of the correlation coefficient used in the time domain. Reliable results with a coherence function greater than 0.95 were not obtained in all subjects for resistance at 2 and $4 \mathrm{~Hz}$, so we have used results for resistance at $6 \mathrm{~Hz}$ $\left(\mathrm{Rrs}_{6}\right)$. The derived values are the mean values of inspiratory and expiratory resistance over the several breaths during the 16 second period and include glottal changes.

Three consecutive sets of measurements over 16 seconds were made while the subject breathed quietly and continuously on the mouthpiece for about two minutes and the mean value was calculated and reported.

To monitor lung volume and breathing pattern during Rrs measurement, the flow signal was integrated to obtain tidal volume and displayed on a strip chart recorder; at the end of each two minute measurement period full inspirations were made to relate tidal volume to TLC and followed by a slow expiratory vital capacity (VC). The average volume at which Rrs was measured was taken as the midtidal lung volume.

Measurements were made in both sitting and supine postures; for measurements in the supine posture the oscillation apparatus was supported by a gantry over the subject, who lay supine on a couch. Care was taken to ensure that a similar, slightly extended position of head and neck and similar support of the cheeks and floor of mouth was sustained in the two postures.

\section{Histamine inhalation}

Buffered solutions of histamine diphosphate were prepared in doubling concentrations up to $32 \mathrm{mg} / \mathrm{ml}$ and were delivered as an aerosol 
with a Mefar dosimeter. A sequence of five puffs of each concentration was inhaled with a deep inspiration from resting end expiration at five second intervals with the subject in the supine position both for the supine study and for the sitting study. A short flexible tube allowed a $90^{\circ}$ turn of the mouthpiece to the mouth. Immediately after inhaling the last puff the subject adopted the appropriate posture and attached the mouthpiece connected to the oscillation apparatus for the measurements, which started about 20 seconds later. The interval between inhaling successive histamine concentrations was five minutes.

\section{PROTOCOL}

The experiment was conducted on four separate days (A, B, C, D).

Day $A$

On day $\mathrm{A}$ responsiveness to histamine in the supine position was examined by using increasing doubling concentrations of inhaled histamine until a value of $\mathrm{Rrs}_{6}$ more than $20 \%$ higher than the saline value was obtained. The provocative concentration causing a $20 \%$ rise in $\operatorname{Rrs}\left(\mathrm{PC}_{20}\right)$ (geometric mean value $9.24 \mathrm{mg} /$ $\mathrm{ml}$ ) was obtained by interpolation on a plot of percentage rise in Rrs versus the logarithm of the concentration (table 1). Doses 1 and 2 of histamine for use on days $C$ and $D$ of the study were chosen from these results as the highest concentration causing a less than $20 \%$ rise in Rrs and the next higher concentration respectively.

\section{Day $B$}

We studied the change in $\mathrm{Rrs}_{6}$ and midtidal lung volume when the subject moved from the sitting to the supine posture (fig 1). The first measurements were made in the sitting position; the subject then remained seated for a further 10 minutes, after which a second set of measurements was made. Immediately after this the subject lay supine on the couch and a further set of measurements was made. The subject remained supine and further measurements were made after 10,20 , and 30 minutes lying supine. After the last set of measurements in the supine posture, the subject sat up and a further set of measurements was made in the sitting position. A final measurement was made 10 minutes after the subject had resumed the sitting position.

\section{Days $C$ and $D$}

The response to histamine was measured on two occasions three hours apart (1200 and 1500 hours) on days $C$ and $D$. This interval was chosen to avoid any tachyphylaxis to histamine $e^{9}$ at the same time as minimising the possibility of variation with time. ${ }^{10} \mathrm{On}$ each day one measurement of the histamine response was made in the sitting and the other in the supine position, but the order was alternated on the two days to allow for any diurnal difference in responsiveness between 1200 and 1500 hours. Before each set of measurements of histamine responsiveness $\mathrm{FEV}_{1}$, VC, TLC, and sGaw were measured in the upright

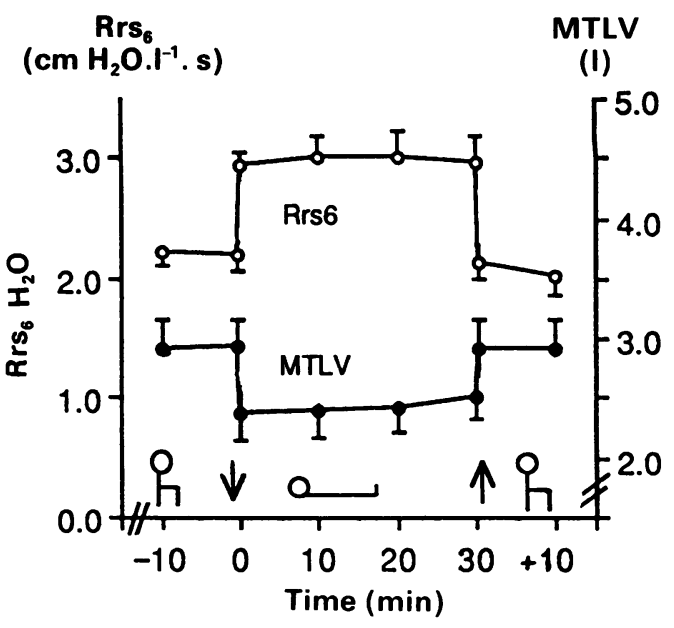

Figure 1 Mean (SEM) changes in respiratory resistance (Rrs ${ }_{6}$ ) and midtidal lung volume (MTLV) during 30 minutes in the supine posture in the eight subjects on day $B$. Conversion to SI unts: $1 \mathrm{~cm} \mathrm{H} \mathrm{H}_{2} \mathrm{O} . \mathrm{l}^{-1} . \mathrm{s}=0.0981 \mathrm{kPa} . \mathrm{l}^{-1} . \mathrm{s}$.

position by spirometry and body plethysmography. When response to histamine was measured in the sitting position an initial measurement of Rrs and midtidal lung volume was made in the supine position followed by a measurement shortly after the subject had adopted the sitting position. The subject then lay supine to inhale the five puffs of a saline control solution and immediately sat up and attached to the mouthpiece of the oscillation apparatus to make the first set of measurements of Rrs (three 16 second runs over about two minutes). Care was taken to avoid coughing, deep inspirations, and expirations during these measurements of Rrs; at the end of this period the subject inhaled to TLC and slowly expired to residual volume. The subject then rested until five minutes had elapsed from the saline dose, resumed the supine posture to inhale five puffs of the first concentration of histamine, and immediately sat up and started a further set of measurements of Rrs and midtidal lung volume as before. This procedure was repeated after a further five minutes for the second concentration of histamine. A similar procedure was followed for examining the effects of saline and histamine in the supine posture except that (1) the subject first completed a baseline set of measurements in the sitting posture followed by a set on adopting the supine position before inhaling saline, and (2) the subject subsequently remained supine throughout. Each challenge procedure lasted about 15 minutes. The two doses of histamine administered to each individual were chosen from the response observed on day $A$; each individual inhaled the same two doses for each of the four tests of histamine response. Histamine was always inhaled in the supine posture to ensure similar deposition of the drug. Provocation concentrations of histamine were obtained by interpolation.

STATISTICAL ANALYSIS

Statistical analysis was performed with paired 
$t$ tests. Provocation concentrations were compared after logarithmic transformation.

\section{Results}

BASELINE LUNG FUNCTION AND PC 20 FOR INHALED HISTAMINE (table 1)

Baseline spirometric values, PEF and sGaw were within the normal range for both measurements on days $C$ and $D$, except in subject 2 who had mild asthma. There were no significant differences between the four groups of measurements; the variation in baseline $\mathrm{FEV}_{1}$ between the four measurements in subject 2 was only $0 \cdot 11$.

\section{CHANGES IN RrS AND MIDTIDAL LUNG VOLUME} WITH POSTURE

Experiments on day B showed that during the 30 minutes in the supine posture there was a mean rise in Rrs of $0.83 \mathrm{~cm} \mathrm{H}_{2} \mathrm{O} .1^{-1}$.s above baseline sitting values $(p=0.01)$ and a mean fall of 0.501 in midtidal lung volume (fig 1$)(p$ $=0.0008$ ). Values of Rrs and midtidal lung volume changed immediately after the subject had adopted the supine posture, remained constant during the 30 minutes, and were restored close to the initial sitting values immediately he or she resumed the sitting posture (fig 1).

The mean (SD) baseline measurements in the eight subjects when they were sitting and supine on days $C$ and $D$ were: midtidal lung volume $2.9(0.8) 1$ sitting, $2.4(0.5) 1$ supine $(\mathrm{p}$ $=0.008) ; \operatorname{Rrs} 2.03(0.44) \mathrm{cm} \mathrm{H}_{2} \mathrm{O} .1^{1-1}$.s sitting, $3.12(0.76) \mathrm{cm} \mathrm{H}_{2} \mathrm{O} .1^{-1}$.s supine $(\mathrm{p}=0.0019)$. Rrs was higher for all subjects when they were supine than when they were seated, and except for subject 3 these values were remarkably consistent in both postures (fig 2).

HISTAMINE RESPONSIVENESS IN SITTING AND SUPINE POSTURES (fig 3, table 2)

In the sitting posture the mean absolute rise in Rrs after histamine inhalation was similar on

Figure 2 Stability of baseline values of respiratory resistance $\left(R_{r} s_{6}\right)$ in each subject in sitting and supine postures on days $C$ and $D:$ mean values of baseline sitting (ए) and supine (口) Rrs preceding studies of responsiveness in the sitting position (horizontal axis) or supine position (vertical axis). Each point represents the mean of two sets of values on days $C$ and $D$. Note that supine values were consistently higher than sitting values. Conversion to SI unts: $1 \mathrm{~cm} \mathrm{H} \mathrm{O}_{2} \mathrm{l}^{-1} . \mathrm{s}=0.0981$ $\mathrm{kPal} \mathrm{l}^{-1} \mathrm{~s}$.

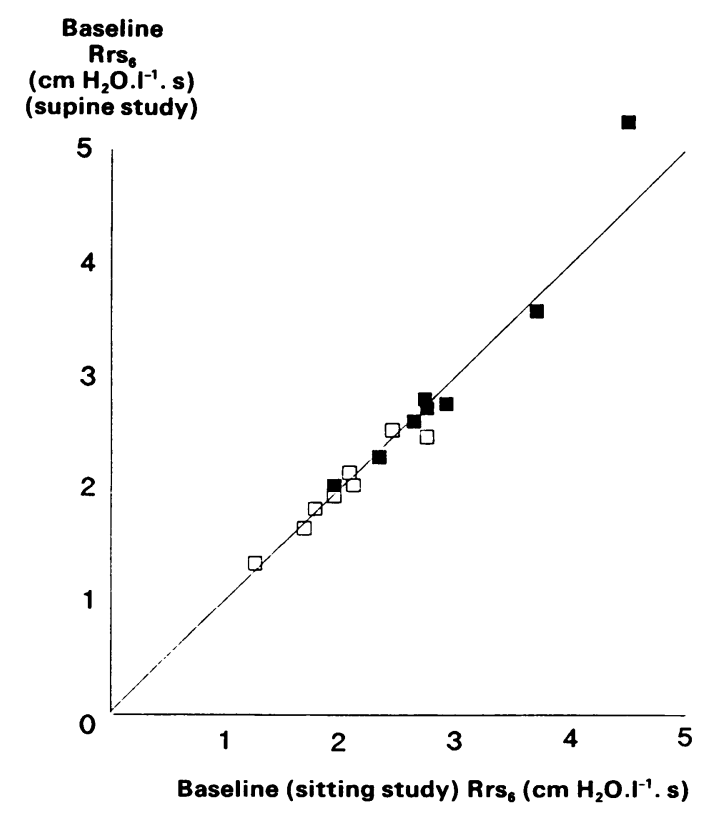

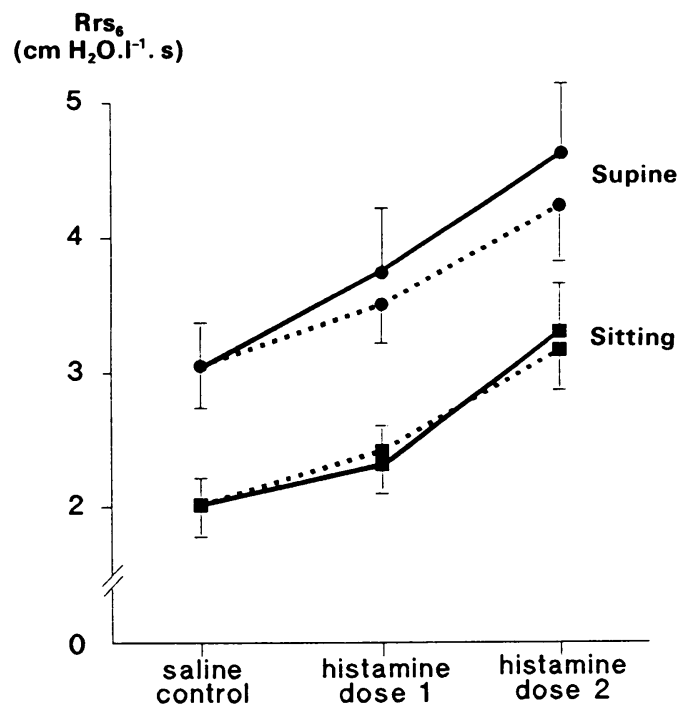

Figure 3 Mean (SEM) changes in respiratory resistance $\left(\operatorname{Rrs}_{6}\right)$ after saline and doses 1 and 2 of histamine in the eight subjects on days $C$ and $D$. Measurements made at 1200 hours (-) and

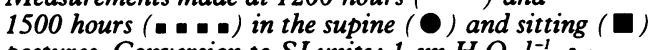
postures. Conversion to SI units: $1 \mathrm{~cm} \mathrm{H} \mathrm{H}_{2} \mathrm{O} . l^{-1} . \mathrm{s}=$ $0.0981 \mathrm{kPal}^{-1} \mathrm{~s}$

the two days (mean (SD) rise in Rrs after the second dose at 1200 hours $1.27(1 \cdot 12) v 1 \cdot 16$ $(0.84) \mathrm{cm} \mathrm{H}_{2} \mathrm{O} .1^{-1} \mathrm{~s}$ at 1500 hours $\left.(\mathrm{p}=0.45)\right)$. In the supine study, however, there was a larger absolute rise in Rrs after histamine challenge at 1200 hours (mean rise after second dose of histamine $1.61(1.15)$ at 1200 hours $v 1 \cdot 18$ $(0.90) \mathrm{cm} \mathrm{H}_{2} \mathrm{O} .1^{-1} \mathrm{~s}$, at 1500 hours $(\mathrm{p}=0.02)$ ). Thus the absolute rise in Rrs was similar in the supine and the sitting posture for the challenges starting at 1500 hours on days $C$ and $D$, whereas at 1200 hours the response was somewhat greater in the supine than the sitting posture. The difference seen in the supine posture at 1200 and 1500 hours was in the same direction as previous reported diurnal variations in airway responsiveness. ${ }^{10}$ Further analysis nevertheless was based on a mean dose-response curve constructed by averaging Rrs values after the two doses of histamine on the two days $(C$ and $D)$.

At the higher dose of histamine the mean (SD) rise in Rrs was $1.21(0.97) \mathrm{cm} \mathrm{H}_{2} \mathrm{O}^{-1} \mathrm{I}^{-1}$ (a

Table 2 Provocation concentrations (PC) of histamine in sitting and supine postures

\begin{tabular}{lll}
\hline & \multicolumn{2}{l}{$\log _{10} P C$} \\
\cline { 2 - 3 } Subject No & Sitting & Supine \\
\hline 1 & 0.793 & 0.667 \\
2 & 1.254 & 1.285 \\
$3^{\star}$ & 1.210 & 1.210 \\
4 & 0.901 & 1.059 \\
5 & 0.892 & 0.724 \\
6 & 0.946 & 1.139 \\
$7 \dagger$ & 1.283 & 1.206 \\
8 & 0.053 & 0.207 \\
Mean (SD) $\log _{10} \mathrm{PC}$ & $0.917(0 \cdot 40)$ & $0.937(0 \cdot 37)$ \\
Geometric mean (mg/ml) & 8.26 & 8.65 \\
\hline *Comparison of $\mathrm{PC}_{60} ;$ tcomparison of $\mathrm{PC}_{25}$ (in the \\
remaining six subjects comparisons were of $\left.\mathrm{PC}_{20}\right)$.
\end{tabular}


mean rise of $65.8 \%$ above baseline) in the sitting position and $1.39(0.99) \mathrm{cm} \mathrm{H}_{2} \mathrm{O}^{-1} \mathrm{~s}$ (mean rise $48.8 \%$ above baseline) in the supine posture $(\mathrm{p}=0 \cdot 26)$. The individual percentage rise in Rrs from baseline on days C and D ranged from $23 \%$ to $223 \%$. Two subjects (subjects 3 and 7) were considerably more responsive to histamine on days $C$ and $D$ than on day A when full dose-response curves were obtained; the rise in Rrs was over $20 \%$ on days $\mathrm{C}$ and $\mathrm{D}$ at the first dose given, and so comparisons were made of $\mathrm{PC}_{60}$ and $\mathrm{PC}_{25}$ respectively. The provocative concentrations of histamine in the sitting and supine positions for each subject (which normalise the results to baseline) were very similar, with a geometric mean value of $8.26 \mathrm{mg} / \mathrm{ml}$ in the sitting position and $8.65 \mathrm{mg} / \mathrm{ml}$ in the supine position $(\mathrm{p}=$ 0.69 ; table 2). Examination of the position and slope of the normalised dose-response curves confirmed that in any individual the whole curves were similar in the two postures.

After saline inhalation mean midtidal lung volume was 2.841 in the sitting position and 2.281 in the supine position, values almost identical to those on day B. After challenge with the higher concentration of histamine midtidal lung volume increased, the rise being slightly greater in the supine than the sitting posture $(0.21(0.24) 1$ sitting $v 0.40(0.38) 1$ supine ( $(\mathrm{p}=0.335))$; thus some of our failure to show a significantly greater rise in Rrs in the supine posture may have been due to the slightly greater increase in midtidal lung volume when airway narrowing developed in the supine posture.

\section{Discussion}

In these experiments inducing a stable $50 \%$ increase in baseline resistance by adopting the supine posture failed to produce a significant increase in responsiveness to a standard dose of inhaled histamine.

\section{CHANGES IN RIS AND MIDTIDAL LUNG VOLUME WITH POSTURE}

Previously it has been difficult to measure resistance in the supine posture because body plethysmography is usually only possible in the sitting position and oesophageal pressure measurements may be subject to artefacts. In the present experiments we used the oscillation technique to study changes in Rrs with posture on five occasions in each individual (once on day $B$, twice each on day $C$ and day $D$ ) and the results were stable with time (fig 1 ) and very similar in repeated experiments (fig 2).

The absolute increases in Rrs in the present subjects when they adopted the supine posture were similar to those recently described by Navajas and colleagues, ${ }^{11}$ who used a similar oscillation technique. The evidence that the increases in Rrs shown by our subjects in the supine posture were due to changes in the intrapulmonary airways and not to increases in resistance of the chest wall or extrathoracic airways is indirect. Thus others have shown only a small increase in chest wall resistance at small lung volumes, ${ }^{12}$ whereas Rodenstein and
Stanescu ${ }^{13}$ have shown that palatal and genioglossal muscles are actively contracted to maintain a widely patent pharyngeal airway in the supine posture in awake subjects. Two studies have shown absolute increases in total airway resistance ${ }^{4}$ and total lung resistance ${ }^{14}$ that were the same as the increase in Rrs in our patients. Most importantly, Linderholm, ${ }^{4}$ who compared results obtained in a conventional body plethysmograph with those obtained in a specially designed plethysmograph in which the subject lay supine, showed that the relation between total airway resistance and lung volume and lung recoil pressure was similar in the sitting and supine postures, indicating that the increase in baseline airway resistance was appropriate for the reduction in lung volume in the supine posture.

Our estimates of the mean reduction in midtidal lung volume under basal conditions ignores any change in TLC, which in practice is slightly lower in the supine than the sitting position. ${ }^{15}$ Direct measurements of functional residual capacity show that the average reduction when the supine posture is adopted is about 0.751 (see review by Svanberg ${ }^{16}$ ). Hence, despite the trend to a slightly greater rise in midtidal lung volume in the supine posture after challenge with the larger dose of histamine, we estimated that midtidal lung volume was still about 0.551 smaller in the supine posture. Reductions in the gas volume of the lung in the supine posture appear to be due to reduction in the neutral volume of the respiratory system, which is largely due to differences in the gravitational effects of the abdominal contents on the position of the diaphragm and to increases in pulmonary blood volume. ${ }^{15}$ We believe therefore that the observed rises in baseline Rrs in the supine position are likely to reflect decreases in airway dimensions, which are passively determined by the reduction in lung volume and recoil pressure and not by changes in bronchomotor tone.

\section{HISTAMINE RESPONSIVENESS AT DIFFERENT} INITIAL AIRWAY CALIBRE

We had expected that bronchial responsiveness would be enhanced at small lung volumes. Reduced lung recoil would be expected to decrease the elastic load against which the bronchial muscle contracts, ${ }^{17} 18$ and interdependence between lung parenchyma and the airway wall weakens as lung volume is reduced. ${ }^{19}$ Reduction of the external airway circumference should reduce internal airway calibre disproportionately and increase wall thickness. ${ }^{1-3}$ But there was only a very slight tendency to increased responsiveness at small lung volume in the present experiments.

We examined various technical factors that might be responsible for our results. Baseline values of Rrs and midtidal lung volume in each posture were remarkably constant (fig 2). Deposition of histamine was controlled by administering it always in the supine posture. The interval of three hours between histamine challenges was chosen to avoid tachyphylaxis to histamine, ${ }^{9}$ and the timing and alternate order of the studies was designed to minimise errors 
in the comparison of postural response to histamine due to diurnal variation in bronchial responsiveness. ${ }^{10}$ We present results of Rrs only at $6 \mathrm{~Hz}$, although change to the supine posture resulted in increases in Rrs at all frequencies, as described also recently by Navajas and colleagues. ${ }^{11}$ In the present subjects there was little frequency dependence of resistance in the sitting posture, but when they adopted the supine posture there was a slight tendency for Rrs to fall between 6 and $16 \mathrm{~Hz}$, presumably related to the reduction in midtidal lung volume; the changes were small and not likely to have attenuated the change in $\mathrm{Rrs}_{6}$ with posture appreciably.

We chose our two doses of histamine on day A so that the larger dose always produced a greater than $20 \%$ rise in Rrs. Because resistance of the chest wall and lung tissue contribute to Rrs the proportionate rise in the airway component is larger. On days $C$ and $D$ the larger dose of histamine produced on average a rise in $\mathrm{Rrs}$ greater than $40 \%$ in both postures, representing a reduction in airway dimensions rather greater than that indicated by the $35 \%$ reduction conventionally used for specific airways conductance. ${ }^{20}$

Results similar to our own were obtained by Ding et $a l,{ }^{17}$ who studied responsiveness to inhaled methacholine at different, voluntarily maintained lung volumes in the sitting posture. These authors did not find any difference in the concentration of methacholine required to double total pulmonary resistance at different lung volumes, though they found that the plateau of increase in resistance often present at FRC was lost when volume was reduced below FRC. Together these results suggest that reduced interdependence between airway narrowing and surrounding parenchyma at small lung volumes becomes important in subjects with mildly increased responsiveness only after considerable airway narrowing has developed.

The result may be different in subjects with active asthma. In such subjects airway dimensions are reduced when they are seated and increases in resistance when they lie flat are larger than in normal subjects. ${ }^{21}$ Moreover, it has been claimed ${ }^{22}$ that lung function in asthmatic subjects may progressively deteriorate when the supine posture is maintained for several hours. Recent studies have shown airway wall thickening ${ }^{3}$ of sufficient severity to enhance responsiveness in vivo. Rises in residual volume occur early in the development of an asthma attack; presumably this is due to airway closure, indicating that the airways are then poorly stabilised against narrowing at small volume. Thus the mechanisms reducing airway dimensions in the supine posture are likely to be amplified in patients with active asthma. The present experiments therefore need to be repeated in subjects with active pathological changes in the airways.

This work was supported by a grant from the Asthma Research Council.

1 Bouhuys A. Effect of posture in experimental asthma in man Am J Med 1963;34:470-6.

2 Freedman BJ. The functional geometry of the bronchi. Bull Eur Physiopathol Respir 1972;8:545-51.

3 James $\mathbf{A L}$, Pare PD, Hogg JC. The mechanics of airway narrowing in asthma. Am Rev Respir Dis 1989;139:242-6.

4 Linderholm $\mathrm{H}$. Lung mechanics in sitting and horizontal postures studied by body plethysmographic methods. $A m$ $J$ Physiol 1963;204:85-91.

5 DuBois AB, Botelho SY, Bedell GN, Marshall R, Comroe JH Jr. A rapid plethysmographic method for measuring thoracic gas volume: a comparison with a nitrogen washout method for measuring functional residual capacity in normal subjects. $J$ Clin Invest 1956;35:322-6.

6 DuBois AB, Botelho SY, Comroe JH Jr. A new method for measuring airway resistance in man using a body plethysmograph: values in normal subjects and in patients with respiratory disease. J Clin Invest 1956;35:327-35.

7 Quanjer $\mathrm{Ph}$. Standardised lung function testing. Bull Eur Physiopathol Respir 1983;19(suppl 5):1-95.

8 Landser FJ, Nagels J, Demedts M, Billiet L, Van de Woestijne KP. A new method to determine frequency characteristics of the respiratory system. J Appl Physio 1976;41:101-6.

9 Manning PJ, Jones GL, O'Byrne PM. Tachyphylaxis to inhaled histamine in asthmatic subjects. $J$ Appl Physiol 1987;63:1572-7.

10 De Vries K, Goei JT, Booy-Noord H, Orie NGM. Changes during 24 hours in the lung function and histamine hyperreactivity of the bronchial tree in asthmatic and bronchitic patients. Int Arch Allergy 1962;20:93-101.

11 Navajas D, Farre R, Rotger MM, Milic-Emili J, Sanchis J. Effect of body posture
Physiol 1988;64:194-9.

12 Nagels J, Landser FJ, Van der Linden L, Clément J, Van der Woestijne KP. Mechanical properties of lungs and chest Woestijne KP. Mechanical properties of lungs and chest
wall during spontaneous breathing. J Appl Physiol 1980; wall during

13 Rodenstein DO, Stanescu DC. Soft palate and oronasal breathing in humans. J Appl Physiol 1984;57:651-7.

14 Behrakis PK, Baydur A, Jaeger MJ, Milic-Emili J. Lung mechanics in sitting and horizontal body positions. Chest 1983;83:643-6.

15 Tenney SM. Fluid volume redistribution and thoracic volume changes during recumbency. J Appl Physiol 1959; 14:129-32.

16 Svanberg L. Influence of posture on the lung volumes, ventilation and circulation of $n$

17 Ding DJ, Martin JG, Macklem PT. Effects of lung volume on maximum methacholine-induced bronchoconstriction on maximum methacholine-induced bronchoconstrictions

18 Mead J, Takishima T, Leith D. Stress distribution in lungs: a model of pulmonary elasticity. J Appl Physiol 1970; 28:596-608.

19 Hughes JMB, Jones HA, Wilson AG, Grant BJB, Pride NB. Stability of intrapulmonary bronchial dimensions during expiratory flow in excised lungs. $J$ Appl Physiol 1974; 31:403-9.

20 Chinet T, Pelle G, Macquin-Mavier I, Lorino H, Harf A. Comparison of the dose-response curves obtained by forced oscillation and plethysmography during carbachol inhalation. Eur Respir J 1988;1:600-5.

21 Coe CI, Pride NB. Immediate changes in respiratory resistance on adopting the supine posture in normal and resistance on adopting the supine posture in normal and
asthmatic subjects [abstract]. Eur Respir $J$ 1988;1:1285.

22 Jonsson E, Mossberg B. Impairment of ventilatory function by supine posture in asthma. Eur J Respir Dis 1984;65: 496-503. 